\title{
Nutritional Dietary Approach for NAFLD: Carbohydrate Restriction or Fat Restriction
}

\author{
Kenichiro Yasutake ${ }^{1}$, Kenji Ohe ${ }^{2}$, Katsumi Imai ${ }^{1}$, Yusuke Murata ${ }^{2}$ and Munechika Enjoji ${ }^{*}$ \\ ${ }^{1}$ Department of Nutritional Sciences, Faculty of Nutritional Sciences, Nakamura Gakuen University, Fukuoka, Japan \\ ${ }^{2}$ Department of Clinical Pharmacology, Faculty of Pharmaceutical Sciences, Fukuoka University, Fukuoka, Japan
}

Received: June 13, 2018; Accepted: July 05, 2018; Published: July 092018

*Corresponding author: Munechika Enjoji, Professor, Department of Clinical Pharmacology, Faculty of Pharmaceutical Sciences, Fukuoka University, 8-19-1 Nanakuma, Jonan-ku, Fukuoka 814-0180, Japan, Tel: +81-92-871-6631; Fax: +81-92-863-0389; E-mail: enjoji@adm.fukuoka-u.ac.jp

\begin{abstract}
The increasing prevalence of nonalcoholic fatty liver disease (NAFLD) in many countries, especially the developed ones, has raised attention for the needs to cope with this disease. It has been reported that NAFLD patients have characteristic overloads of carbohydrate and lipid intake, and that their restriction improves the patient's disease status. Then, which of the two has a better effect: carbohydrate or lipid intake restriction? This review will summarize the pros and cons in assessing NAFLD by carbohydrate or lipid restriction, and will discuss about the proper nutritional intake for NAFLD.
\end{abstract}

Keywords: Nonalcoholic Fatty Liver Disease; Nutrition Assessment; Energy Restriction; Whole Grain; N-3 Polyunsaturated Fatty Acids;

\section{Introduction}

Nonalcoholic fatty liver disease (NAFLD) is the most common liver disease in developed countries [1-3], an emerging major health problem in the Asian region [4]. Its increasing prevalence has no relation with race, gender, or age [5-9], and is a problematic issue in many countries. NAFLD patients are known to have an overload of carbohydrate or lipid [10-15]. Indeed, it has been reported that hepatic fat increases in proportion with excess intake of glucose [16], fructose [16, 17], or lipid [17-19]. Moreover, the expression level of lipid synthesis genes in the liver differs between carbohydrate or lipid intake [20], and thus the development of NAFLD depends on the specific nutrient. On the other hand, carbohydrate or lipid restriction has been reported to improve NAFLD with their order of merit [21, 22]. This review will focus on the effects as well as problematic issues about carbohydrate or lipid restriction in NAFLD patients, and discuss on the adequate nutritional treatment to assess NAFLD.

\section{Carbohydrates}

Carbohydrates can be found in grain, fruits, vegetables, dairy products, and is a major source of energy. It is a polymerized product of a minimum monosaccharide unit and can be categorized by chemical and physiological characteristics as shown in table 1 [23]. In addition, the extent of digestibility to digestive enzymes categorizes carbohydrates into "available carbohydrates" and "dietary fiber". Protein and lipids that bind to carbohydrates are also categorized into carbohydrates, and such compounds are called "complex carbohydrates", while others are called "simple carbohydrates". Moreover, the so called "invert sugar", a product invented by scientific evolution,

Table 1: The major dietary carbohydrates [23]

\begin{tabular}{|c|c|c|}
\hline Class (DP*) & Subgroup & Principal components \\
\hline \multirow{3}{*}{ Sugars } & Monosaccharides & Glucose, fructose, galactose \\
\hline & Disaccharides & Sucrose, lactose, maltose, trehalose \\
\hline & Polyols (sugar alcohols) & $\begin{array}{l}\text { Sorbitol, mannitol, lactitol, xylitol, } \\
\text { erythritol, isomalt, maltitol }\end{array}$ \\
\hline \multirow{2}{*}{$\begin{array}{l}\text { Oligosaccharides (3-9): short- } \\
\text { chain carbohydrates }\end{array}$} & Malto-oligosaccharides ( $\alpha$-glucans) & Maltodextrins \\
\hline & Non- $\alpha$-glucan oligosaccharides & $\begin{array}{l}\text { Raffinose, stachyose, fructo and galacto oligosaccharides, } \\
\text { polydextrose, inulin }\end{array}$ \\
\hline \multirow[b]{2}{*}{ Polysaccharides $(\geq 10)$} & Starch ( $\alpha$-glucans) & Amylose, amylopectin, modified starches \\
\hline & Non-starch polysaccharides & $\begin{array}{l}\text { Cellulose, hemicellulose, pectin, arabinoxylans, } \beta \text {-glucan, } \\
\text { glucomannans, plant gums and mucilages, } \\
\text { hydrocolloids }\end{array}$ \\
\hline
\end{tabular}


is categorized into carbohydrates [24]. "Invert sugar" is defined as carbohydrates not found in nature such as white sugar, black sugar, corn syrup, high-fructose corn syrup, pancake syrup, and concentrated fruit juice. Representative examples of food that include these are soft drinks, fruit juice, desserts, frozen desserts, and canned food. "Invert sugar" is frequently used in the food industry of developed countries, and these monosaccharides are a major source of intake in these countries. Thus, concerning nutritional treatment, intake should be referred to as sugars instead of carbohydrates, but many reports do not designate the two, properly. Moreover, the glycemic index of carbohydrates should also be discussed, not only its volume.

\section{Good and bad carbohydrates for NAFLD}

Inappropriate consumption of available carbohydrates or sugars causes hyperglycemia due to insulin resistance and glucose overload in the liver. The stimulated insulin secretion, via activation of de novo lipogenesis in the liver, converts these carbohydrates to glycogen or free fatty acids (FFA). FFA is also called non-esterified fatty acid (NEFA). Production of FFA increases triacylglycerols and cholesterol-esters in the liver, and subsequently stores lipids in the liver $[13,25,26]$. On the other hand, excess consumption of monosaccharides is known to induce insulin resistance $[27,28]$. Insulin resistance in adipose tissue increases NEFA [25] and the resulting hyperinsulinemia stimulate de novo lipogenesis in the liver [26].

Recently, soft drinks are the main cause of sugar overconsumption and deeply related with NAFLD. NAFLD patients have been reported to consume over twice as much soft drinks daily compared with the general population, as well as the drinking frequency also significantly high [29-31]. In addition, the study by Abid et al. showed that an increase in number of consumed soft drink bottles correlates with the severeness of fatty liver evaluated by abdominal ultrasonography. This shows soft drink consumption is a strong predictive factor of fatty liver [31].

Onthe other hand,compilingevidence showed thatappropriate consumption of non-processed whole grain, consisting of dietary fiber and vitamins or minerals with anti-oxidizing function, is beneficial for NAFLD [32]. An epidemiological study showed nonprocessed whole grain consumption reduces abdominal fat, a risk factor of NAFLD [33], and a randomized intervention study showed that it improves obesity, lipid disorders, and metabolic syndrome [34]. A meta-analysis study that investigated the effect of whole grain showed decreased risks of heart disease $[35,36]$, and type 2 diabetes mellitus [35, 37] with a decrease in fasting insulin level [35, 38], blood serum lipid level [35], and body weight [39], indicating improved effect on these NAFLDrelated features. These reports imply the advantages of adequate everyday consumption of whole grain in preventing or improving the disease status in NAFLD patients.

In summary, NAFLD has a deep relationship with carbohydrates, and we should be aware that specific carbohydrates cause development or progression of the disease, while others may improve the pathophysiological features.

\section{Carbohydrate restriction for NAFLD patients: how to take carbohydrate effectively?}

Randomized Clinical Trials (RCTs) that analyzed the effect of carbohydrate restriction (some studies do not show whether the restricted nutrient is carbohydrate or sugar, so we designate both as carbohydrate-restricted meals, here) show each study has a different definition of carbohydrate restriction: some state carbohydrate restriction as ketogenic meals less than 20 g per day [40] or as energy ratio down to $8 \%$ [41]; others as weak restrictions like energy ratio down to $30 \%$ [42-44] or $40 \%$ [22, 45-48]. In addition, the target population of these randomized controlled trials in these meta-analysis studies shows that while carbohydrate restriction has a significant effect on reducing the intra-hepatic lipid content, it shows no effect on lowering the elevated liver enzyme levels [49], and concluding the effect is marginal. A meta-analysis that summarized 19 RCTs studying the effect of carbohydrate on obese subjects show a comparison of low carbohydrate group (1364 subjects) and control group (1406 subjects). Almost all studies showed that changes in body weight is less than $2 \mathrm{~kg}$ and the difference of the total average is less than $1 \mathrm{~kg}$, with almost no effect of carbohydrate restriction [50]. Decreasing intake or energy ratio of carbohydrate would result in a relative increase of the ratio of protein or lipid. This increase of the amount or ratio of lipid is a high-risk factor of NAFLD. Moreover, restriction of carbohydrates would result in shortage of whole grain such as dietary fiber or unprocessed grain that may improve the pathological state in NAFLD. Nonetheless, it should be noted that the effective amount or ratio of low carbohydrate diet is not clear, with issues such as the quantity or quality of carbohydrates, as well as effect, safety, and long term prognosis, questionable.

\section{Lipids}

Lipids are an important source of metabolic energy, material necessary for synthesizing compounds (essential fatty acids), regulators of gene expression, and are precursors of other nutrients such as fat-soluble vitamins in gastrointestinal region and plasma. Lipids are water-insoluble and soluble in organic acid [51]. They can be categorized to simple, compound, and derived lipids (Table 2) [52] and those with important nutritional roles are fatty acid, neutral fat, phospholipid, glycolipid, and sterol. Fatty acids have a carboxyl group at the end of a hydrocarbon chain (consisted of only hydrogen and carbon) made of 4-36 of carbons. Energy metabolism is done through the carboxyl group, as a source of energy, and also a component of the cell membrane. Fatty acid is consisted of: saturated fatty acid; no double bonds between the carbons, monounsaturated fatty acid; one double bond between carbons, and polyunsaturated fatty acid (PUFA); two or more double bonds between carbons. PUFA can be categorized into n-3 and n- 6 fatty acids depending on the location of the first double bond from the methyl group terminal. Unsaturated fatty acids with double bonds have geometric isomers of Trans and cis. In nature, almost all the unsaturated fatty acids are cis, and only few are Trans [53]. 


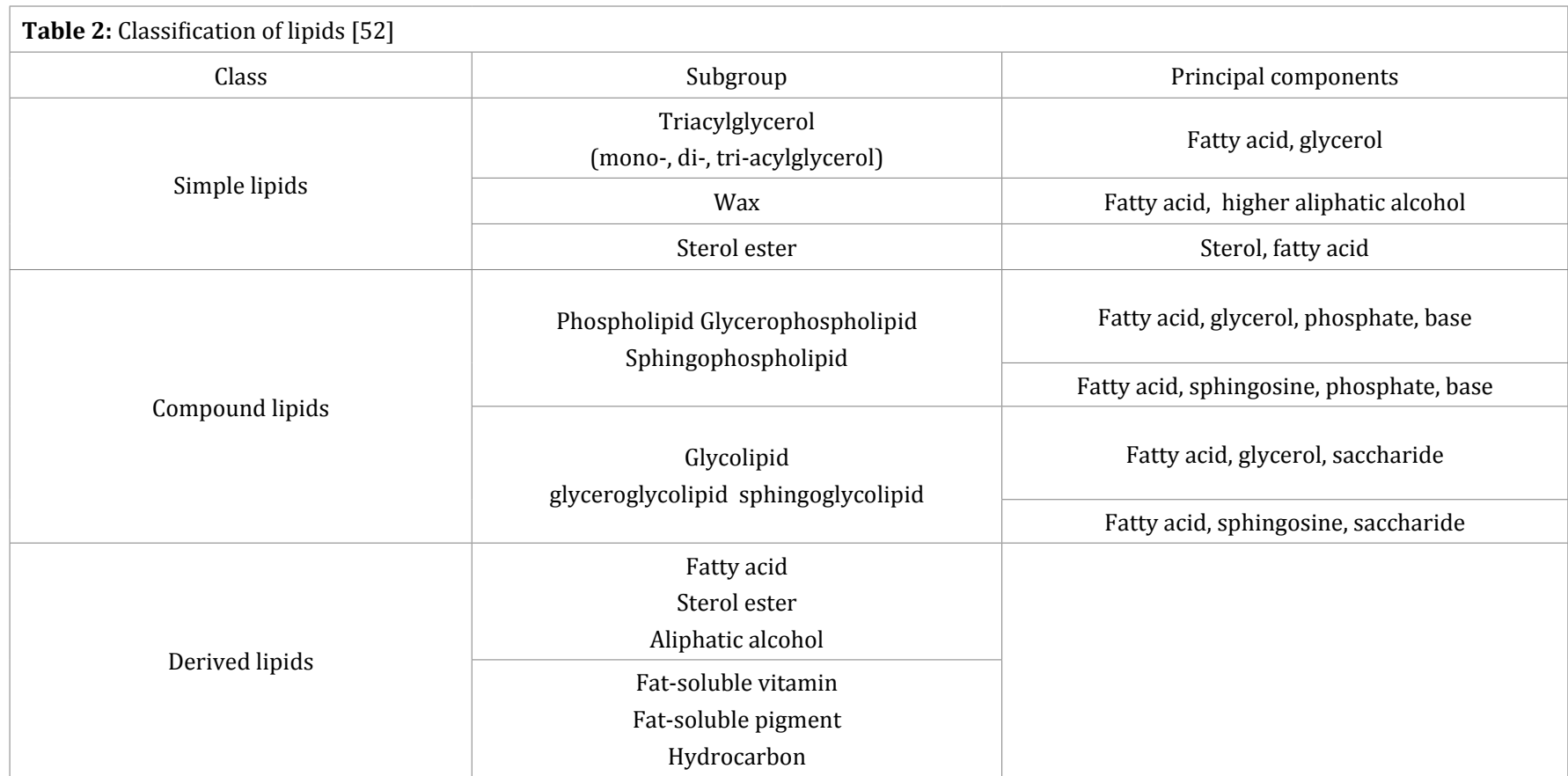

\section{Good and bad lipids for NAFLD}

Excess or inappropriate intake of fatty acid induces insulin resistance, activation of lipoprotein lipase in adipose tissue by insulin stimulation, decomposition of triacylglycerol in blood through many genetic alterations in the fatty acid metabolic pathway, and free fatty acid uptake by adipocytes increasing triacylglycerol storage. This induces increase of lipid storage in the muscle, increase of triacylglycerol in the liver, an increase of cholesterol-ester [13]. Among the fatty acids, excess intake of saturated fatty acid is implicated in possible increase of insulin resistance and morbidity of type 2 diabetes mellitus that are directly involved in the disease status of NAFLD [54, 55]. The insulin resistance in adipose tissue induces increase of NEFA [25] which induces hyperinsulinemia that stimulates de novo lipogenesis in the liver [26]. Epidemiological studies have shown that NAFLD patients have excess total intake of saturated fatty acid. Musso et al. have used a seven-day dietary recording method to compare nutritional intake between non-alcoholic steatohepatitis (NASH) patients and normal controls, and found that NASH patients have a significantly higher intake of saturated fatty acids [14]. Moreover, the investigation of Toshimitsu et al. has shown that intake of lipids and saturated fatty acid was higher in both NASH and NAFLD patients [56]. Vilar et al. have reported that the percentage of lipid energy intake and saturated fatty acid intake was $37.5 \%$ and $10.1 \%$, respectively, in NASH patients. Since this was significantly high than that in NAFLD patients, they reported that these lipids may be one of the causes of transition from NAFLD to NASH [57]. Conversely, a crossover comparison study of pre-menopause obese women and obese middle-age men for intervention of lipids and saturated fatty acid showed that it decreased liver fat $[58,59]$. The energy per kg of lipids is $9 \mathrm{kcal} / \mathrm{kg}$, which is higher than carbohydrates and protein that are $4 \mathrm{kcal} / \mathrm{kg}$. It is believed that this influences obesity, but animal studies show that when the total energy intake per day is the same, the higher proportion of fat increased the tendency to induce obesity [60]. Ha et al. have shown that high-fat diet for a certain period resulted in an increase of body weight, liver fat composition, blood sugar level, and liver inflammation along with the increase of percentage of lipid energy in mouse studies [61]. Other studies have shown that high-fat diet induces liver fat and insulin resistance [62], increase of TNF- $\alpha$ and inflammation [63]. In other words, excess lipid intake easily induces obesity despite the same energy level. The possible mechanism is due to differences in the nutrition resorption pathway and conversion to triacylglycerol. On the other hand; reports have shown that n-3 PUFA may improve the pathogenesis of NAFLD. A study where n-3 PUFA was administered for 12 months, liver function and various blood serum markers for NAFLD improved [64]. In addition, a random comparison study of adolescent NAFLD patients administered of n-3 PUFA and improvement of eating habits (carbohydrate $50 \%$, protein $20 \%$, and lipid $30 \%$ ) for 12 months improved liver steatosis and liver function compared to placebo [65]. In addition, a two-group randomized control study showed that the administered group had significantly improved levels of liver function, lipid metabolic markers, inflammation marker [C-reactive protein (CRP) level], oxidative stress level [malondialdehyde (MDA)] and liver fibrosis markers (Type IV collagen, pro-collagen type III pro-peptide) [66]. On the other hand, a 12-month double-blind randomized placebo-controlled clinical trial study of NASH complicated of type 2 diabetes mellitus showed that PUFA administration does not contribute to the improvement of NASH pathogenesis [67]. Taken together, lipids are deeply involved in NAFLD, but it must be kept in mind that some induce or exacerbate diseases as others may improve them. 


\section{Lipid restriction for NAFLD patients: what is effective lipid intake?}

It has been shown that extremely-low lipid diet (energy: 1200 kcal, carbohydrate: $50 \%$, protein: $43 \%$, fat: 7\%, dietary fiber 12 g) by a liquid dietary formula decreases hepatic triacylglycerol content in type 2 diabetes mellitus complicated NAFLD patients [68]. Utzschneider et al. have reported that hepatic fat level significantly decreased in obese elderly subjects by LSAT diet (lipid: $23 \%$, saturated fatty acid: $7 \%$, glycemic index: 55 ), but not by HSAT diet (lipid: $43 \%$, saturated fatty acid: $24 \%$, glycemic index: $>70$ ), in a 4-week random assignment study [69]. NAFLD patients with a 3-day diet of 30\% lipid energy have been reported that $14.9 \%$ of hepatic triacylglycerol is directly used from dietary fat [70]. On the other hand, an 8-week intervention of NAFLD patients by a 30\% lipid diet modified from the DASH diet (carbohydrate: $52-55 \%$, protein: $16-18 \%$, total fat: $30 \%$; originally designed to be rich in fruits, vegetables, whole grains, and low-fat dairy products and low in saturated fats, cholesterol and refined grains) improved high-sensitivity CRP, MDA, nitric oxide (NO) and glutathione (GSH) as well as liver function and glucose and lipid metabolic markers [71]. These RCTs analyzed small target populations but show that NAFLD may be improved by extremely-low or mildly-low lipid restrictions, but leaving the appropriate lipid intake level unknown. In addition, the specific lipid and the food taken together may have changed the effect. Moreover, the choice of high-protein or normal-protein intake on this low-fat diet may also have had an effect [72].

Lowering fat energy intake would mean to proportionally increase the energy level or percentage of carbohydrate or protein intake. Especially, the increase of carbohydrate level or percentage is known as a risk-factor for NAFLD. If fat is restricted, the n-3 PUFA that may improve NAFLD may also become of shortage. Nonetheless, the present consensus is that the effect of fat restriction on NAFLD is limited, and it should be noted that many issues are left to be answered such as the effective level or percentage of fat, or whether level or percentage is more important.

\section{An effective diet therapy for NAFLD: carbohydrate vs. fat restriction}

We have shown the effect of carbohydrate and fat restriction on NAFLD patients, but which of the two has the better effect? Haufe et al. have conducted a 6-month intervention random assignment comparison study on 170 overweight and obese subjects for low-carbohydrate diet (carbohydrate $\geq 90$ g, protein $0.8 \mathrm{~g} / \mathrm{kg}$, fat $\geq 30 \%$ ) or low-fat diet (fat $\leq 20 \%$, protein $0.8 \mathrm{~g} / \mathrm{kg}$ ). A total of 102 subjects completed the study with proper intake of each group, and resulted in improved body weight, AST and ALT levels, intra-hepatic lipids, whole body insulin resistance, and hepatic insulin resistance. Both low-carbohydrate or low-fat diet showed the same result that decrease of energy intake and good compliance would improve obesity that induces NAFLD and other diseases [21]. Sacks et al. divided 811 obese subjects into 4 groups (group A; carbohydrate $60 \%$, fat $20 \%$, protein $15 \%$, group B; carbohydrate $55 \%$, fat $20 \%$, protein $25 \%$, group C; carbohydrate $45 \%$, fat $40 \%$, protein $15 \%$, group D; carbohydrate $35 \%$, fat $40 \%$, protein $25 \%$ ) taking the predetermined nutritional intake for 2 years and checked for change in body weight. The results of this carefully designed study showed that body weight did not change when the energy intake was equal despite the source [73]. Comparison by meta-analysis of 48 randomized trials using diet methods without dietary intervention targeted to 7286 subjects of obese overweight patients showed that low-carbohydrate and low-fat correlated well with bodyweight reduction, but no difference between dietary methods. These results showed that a diet method with good compliance should be recommended to a patient [74]. In addition, the influence of low-carbohydrate, low-fat (in comparison to Mediterranean diet) on bodyweight reduction was analyzed by four meta-analysis trials (13-24 trials) and found that adherence to the predetermined diet and exercise correlated most well with bodyweight reduction and improvement of disease [72, 75-77]. There was almost no difference between various dietary restrictions on bodyweight reduction ratio, and since the results were not consistent, some people even say that the "low-carbohydrate vs. low-fat" has no meaning [78]. In other words, before conducting restriction of a specific nutrient, managing the biological, behavioral, and environmental factors related to improving dietary and exercise adherence of lifestyle is the most important issue to be followed [78]. Nonetheless, the routine lipid restriction for patients with excess carbohydrate intake or carbohydrate restriction for patients with excess fat intake would be inappropriate from the aspect of disease pathogenesis or nutritional balance of dietary intake.

We propose that before mechanically conducting a choice between carbohydrate or fat restriction, a "nutritional diagnosis" based upon nutritional assessment of each patient should be made. Then, restriction of the excess nutrient should be corrected by this "nutritional diagnosis". The speed of eating [79, 80], the extent of mastication [81, 82], and the order of eating [83, 84] have also been shown to change bodyweight and metabolism, making the effect of a specific nutrient or active ingredient not the sole issue of argument. In addition, restricting carbohydrates or fat should concern the subjects' eating habits, dietary culture, local tradition, dietary environment or accessibility to purchased food (how easily the subject can purchase food). According to the "Nutrition Therapy Recommendations for the Management of Adults with Diabetes" of 2013 [85], personal and cultural preferences, lifestyle, therapeutic goals are different between patients, and thus nutrition therapy must also be conducted differentially, and that no standard evidence-based meal plan exists. The importance of nutrition therapy is that it fits with each lifestyle of personal habitual preferences. This applies to all diseases including diabetes where nutritional and dietary therapy is necessary. Taken together, nutritional and dietary therapy of NAFLD should be based upon assessment, nutritional diagnosis, and understandings of personal preferences, with concomitant settings of a nutritional care plan where energy intake can easily be decreased. 


\section{Conclusions}

We have discussed here the effect, the problems, and the limitations of carbohydrate and lipid restriction of nutritional therapy for NAFLD patients. Nutritional approaches focusing on one sole nutrient such as carbohydrate or lipid can sometimes be inappropriate and unsuitable for a patient. Nutritional approaches of NAFLD patients must be initially done by a thorough nutritional assessment of the patient's life history, with a subsequent nutritional diagnosis, and a total care approach must be conducted thereafter to improve the pathogenic condition of the patient's disease.

\section{Conflict of interest and funding disclosure}

This article did not receive any specific grant from funding agencies in the public, commercial, or not-for-profit sectors.

\section{References}

1. Lazo M, Clark JM. The epidemiology of nonalcoholic fatty liver disease: a global perspective. Semin Liver Dis. 2008;28(4):339-350. doi: 10.1055/s-0028-1091978

2. Ratziu V, Bellentani S, Cortez-Pinto H, Day C, Marchesini G. A position statement on NAFLD/NASH based on theEASL 2009 special conference. J Hepatol. 2010;53(2):372-384. doi: 10.1016/j.jhep.2010.04.008

3. Younossi ZM, Stepanova M, Afendy M, Fang Y, Younossi Y, Mir H, Srishord M, et al. Changes in the prevalence of the most common causes of chronic liver diseases in the United States from 1988 to 2008. Clin Gastroenterol Hepatol. 2011;9(6):524-530. doi:10.1016/j. cgh.2011.03.020

4. Farrell GC, Wong VW, Chitturi S. NAFLD in Asia--as common and important as in the West. Nat Rev Gastroenterol Hepatol. 2013;10(5):307-318. doi: 10.1038/nrgastro.2013.34

5. Browning JD, Szczepaniak LS, Dobbins R, Nuremberg P, Horton JD. Prevalence of hepatic steatosis in an urban population in the United States: impact of ethnicity. Hepatology. 2004; 40(6):1387-1395. doi: 10.1002/hep.20466

6. Welsh JA, Karpen S, Vos MB. Increasing prevalence of nonalcoholic fatty liver disease among United States adolescents, 1988-1994 to 2007-2010. J Pediatr. 2013;162(3):496-500. doi: 10.1016/j. jpeds.2012.08.043

7. Patton HM, Sirlin C, Behling C, Middleton M, Schwimmer JB, Lavine JE. Pediatric nonalcoholic fatty liver disease: a critical appraisal of current data and implications for future research. J Pediatr Gastroenterol Nutr. 2006;43(4):413-427. doi: 10.1097/01.mpg.0000239995.58388.56

8. Papandreou D, Rousso I, Mavromichalis I. Update on non-alcoholic fatty liver disease in children. Clin Nutr. 2007;26(4):409-415. doi: 10.1016/j.clnu.2007.02.002

9. Schwimmer JB, Deutsch R, Kahen T, Lavine JE, Stanley C, Behling C. Prevalence of fatty liver in children and adolescents. Pediatrics. 2006;118(4):1388-1393. doi: 10.1542/peds.2006-1212

10.Zelber-Sagi S, Nitzan-Kaluski D, Goldsmith R, Webb M, Blendis L, Halpern Z, Oren R, et al. Long term nutritional intake and the risk for non-alcoholic fatty liver disease (NAFLD): a population based study. J Hepatol. 2007;47(5):711-717. doi: 10.1016/j.jhep.2007.06.020

11.Zelber-Sagi S, Ratziu V, Oren R. Nutrition and physical activity in NAFLD: an overview of the epidemiological evidence. World J Gastroenterol. 2011;17(29):3377-3389. doi: 10.3748/wjg.v17.i29.3377
12. Solga S, Alkhuraishe AR, Clark JM, Torbenson M, Greenwald A, Diehl AM, Magnuson T, et al. Dietary composition and nonalcoholic fatty liver disease. Dig Dis Sci. 2004;49:1578-1583. PMID: 15573908.

13. Zivkovic AM, German JB, Sanyal AJ. Comparative review of diets for the metabolic syndrome: implications for nonalcoholic fatty liver disease. Am J Clin Nutr. 2007;86(2): 285-300. doi: 10.1093/ajcn/86.2.285

14. Musso G, Gambino R, De Michieli F, Cassader M, Rizzetto M, Durazzo $\mathrm{M}$, Fagà $\mathrm{E}$, et al. Dietary habits and their relations to insulin resistance and postprandial lipemia in nonalcoholic steatohepatitis. Hepatology. 2003;37(4): 909-916. doi: 10.1053/jhep.2003.50132

15. Yasutake K, Nakamuta M, Shima Y, Ohyama A, Masuda K, Haruta $\mathrm{N}$, Fujino $\mathrm{T}$, et al. Nutritional investigation of non-obese patients with non-alcoholic fatty liver disease: the significance of dietary cholesterol. Scand J Gastroenterol. 2009;44(4):471-477. doi: $10.1080 / 00365520802588133$

16. Ngo Sock ET, Le KA, Ith M, Kreis R, Boesch C, Tappy L. Effects of a shortterm overfeeding with fructose or glucose in healthy young males. Br J Nutr. 2010;103(7):939-943. doi: 10.1017/S0007114509992819

17. Sobrecases H, Lê KA, Bortolotti M, Schneiter P, Ith M, Kreis R, Boesch C, et al. Effects of short-term overfeeding with fructose, fat and fructose plus fat on plasma and hepatic lipids in healthy men. Diabetes Metab. 2010;36(3):244-6. doi: 10.1016/j.diabet.2010.03.003

18. Brøns C, Jensen CB, Storgaard H, Hiscock NJ, White A, Appel JS, Jacobsen $\mathrm{S}$, et al. Impact of short-term high-fat feeding on glucose and insulin metabolism in young healthy men. J Physiol. 2009;587(pt 10):2387-2397. doi: 10.1113/jphysiol.2009.169078

19. Bortolotti M, Kreis R, Debard C, Cariou B, Faeh D, Chetiveaux M, Ith M, et al. High protein intake reduces intrahepatocellular lipid deposition in humans. Am J Clin Nutr. 2009;90(4): 1002-1010. doi: 10.3945/ ajcn.2008.27296

20. Sanchez J, Palou A, Pico C. Response to carbohydrate and fat refeeding in the expression of genes involved in nutrient partitioning and metabolism: striking effects on fibroblast growth factor-21 induction. Endocrinology. 2009;150(12):5341-5350. doi: 10.1210/en.20090466

21. Haufe S, Engeli S, Kast P, Böhnke J, Utz W, Haas V, Hermsdorf M, et al. Randomized comparison of reduced fat and reduced carbohydrate hypocaloric diets on intrahepatic fat in overweight and obese human subjects. Hepatology. 2011;53(5):1504-1514. doi: 10.1002/ hep. 24242

22. Kani AH, Alavian SM, Esmaillzadeh A, Adibi P, Azadbakht L. Effects of a novel therapeutic diet on liver enzymes and coagulating factors in patients with non-alcoholic fatty liver disease: a parallel randomized trial. Nutrition. 2014;30(7-8):814-821. doi: 10.1016/j. nut.2013.11.008

23. Cummings JH, Stephen AM. Carbohydrate terminology and classification. Eur J Clin Nutr. 2007;61(Suppl 1):S5-18. doi: 10.1038/ sj.ejcn.1602936

24. United States Department of Agriculture. Report of the dietary guidelines advisory committee on dietary guidelines for Americans, 2010. Available online: https://www.nutriwatch.org/05Guidelines/ dga_advisory_2010.pdf.

25. McLaughlin T, Yee G, Glassford A, Lamendola C, Reaven G. Use of a two-stage insulin infusion study to assess the relationship between insulin suppression of lipolysis and insulin-mediated glucose uptake in overweight/obese, nondiabetic women. Metabolism. 2011;60(12):1741-1747. doi: 10.1016/j.metabol.2011.05.008 
26. Browning JD, Horton JD. Molecular mediators of hepatic steatosis and liver injury. J Clin Invest. 2004;114(2):147-152. doi: 10.1172/ JCI22422

27. Proietto J, Filippis A, Nakhla C, Clark S. Nutrient-induced insulin resistance. Mol Cell Endocrinol. 1999;151(1-2):143-149.

28. Bessesen DH. The role of carbohydrates in insulin resistance. J Nutr. 2001;131(10):2782S-2786S. doi: 10.1093/jn/131.10.2782S

29. Assy N, Nasser G, Kamayse I, Nseir W, Beniashvili Z, Djibre A, Grosovski $\mathrm{M}$, et al. Soft drink consumption linked with fatty liver in the absence of traditional risk factors. Can J Gastroenterol. 2008;22(10):811-816.

30. Ouyang X, Cirillo P, Sautin Y, McCall S, Bruchette JL, Diehl AM, Johnson $\mathrm{RJ}$, et al. Fructose consumption as a risk factor for non-alcoholic fatty liver disease. J Hepatol. 2008;48(6):993-999. doi: 10.1016/j. jhep.2008.02.011

31. Abid A, Taha O, Nseir W, Farah R, Grosovski M, Assy N. Soft drink consumption is associated with fatty liver disease independent of metabolic syndrome. J Hepatol. 2009; 51(5):918-924. doi: 10.1016/j. jhep.2009.05.033

32. Ross AB, Godin JP, Minehira K, Kirwan JP. Increasing whole grain intake as part of prevention and treatment of nonalcoholic Fatty liver disease. Int J Endocrinol. 2013:585876. doi: 10.1155/2013/585876

33. Nicola M. McKeown, Makiko Yoshida, M. Kyla Shea, Paul F. Jacques, Alice H. Lichtenstein, Gail Rogers, Sarah L. Booth, et al. Whole-grain intake and cereal fiber are associated with lower abdominal adiposity in older adults. J Nutr. 2009;139(10):1950-1955. doi: 10.3945/ jn.108.103762

34. Katcher HI, Legro RS, Kunselman AR, Gillies PJ, Demers LM, Bagshaw DM, Kris-Etherton PM, et al. The effects of a whole grain-enriched hypocaloric diet on cardiovascular disease risk factors in men and women with metabolic syndrome. Am J Clin Nutr. 2008;87(1):79-90. doi: 10.1093/ajcn/87.1.79

35. Ye EQ Chacko SA, Chou EL, Kugizaki M, Liu S. Greater whole-grain intake is associated with lower risk of type 2 diabetes, cardiovascular disease, and weight gain. J Nutr. 2012;142(7):1304-1313. doi: 10.3945/jn.111.155325

36. Mellen PB, Walsh TF, Herrington DM. Whole grain intake and cardiovascular disease: a meta-analysis. Nutr Metab Cardiovasc Dis. 2008;18(4):283-290. doi: 10.1016/j.numecd.2006.12.008

37. de Munter JS, Hu FB, Spiegelman D, Franz M, van Dam RM. Whole grain, bran, and germ intake and risk of type 2 diabetes: a prospective cohort study and systematic review. PLoS Med. 2007;4(8):e261. doi: 10.1371/journal.pmed.0040261

38. Nettleton JA, McKeown NM, Kanoni S, Lemaitre RN, Hivert MF, Ngwa J, et al. Interactions of dietary whole-grain intake with fasting glucoseand insulin-related genetic loci in individuals of European descent: a meta-analysis of 14 cohort studies. Diabetes care. 2010;33(12):26842691. doi: $10.2337 /$ dc10-1150

39. Mozaffarian D, Hao T, Rimm EB, Willett WC, Hu FB. Changes in diet and lifestyle and long-term weight gain in women and men. N Engl J Med. 2011;364(25):2392-2404. doi: 10.1056/NEJMoa1014296

40. Tendler D, Lin S, Yancy WS Jr, , Mavropoulos J, Sylvestre P, Rockey DC, et al. The effect of a low-carbohydrate, ketogenic diet on nonalcoholic fatty liver disease: a pilot study. Dig Dis Sc.i 2007;52(2):589-593. doi: 10.1007/s10620-006-9433-5

41. Browning JD, Baker JA, Rogers T, Davis J, Satapati S, Burgess SC. Shortterm weight loss and hepatic triglyceride reduction: evidence of a metabolic advantage with dietary carbohydrate restriction. Am J Clin
Nutr. 2011;93(5):1048-1052. doi: 10.3945/ajcn.110.007674

42. Ryan MC, Itsiopoulos C, Thodis T, Ward G, Trost N, Hofferberth S, et al. The Mediterranean diet improves hepatic steatosis and insulin sensitivity in individuals with non-alcoholic fatty liver disease. J Hepatol. 2013;59(1):138-143. doi: 10.1016/j.jhep.2013.02.012

43. Volynets V, Machann J, Kuper MA, Maier IB, Spruss A, Königsrainer A, et al. A moderate weight reduction through dietary intervention decreases hepatic fat content in patients with non-alcoholic fatty liver disease (NAFLD): a pilot study. Eur J Nutr. 2013;52(2):527-535. doi: 10.1007/s00394-012-0355-z

44. de Luis DA, Aller R, Izaola O, Gonzalez Sagrado M, Conde R. Effect of two different hypocaloric diets in transaminases and insulin resistance in nonalcoholic fatty liver disease and obese patients. Nutr Hosp. 2010;25(5):730-735.

45. Rodriguez-Hernandez H, Cervantes-Huerta M, Rodriguez-Moran M, Guerrero-Romero F. Decrease of aminotransferase levels in obese women is related to body weight reduction, irrespective of type of diet. Ann Hepatol. 2011;10(4):486-492.

46. Elias MC, Parise ER, de Carvalho L, Szejnfeld D, Netto JP. Effect of 6-month nutritional intervention on non-alcoholic fatty liver disease. Nutrition. 2010;26(11-12):1094-1099. doi: 10.1016/j. nut.2009.09.001

47. Thomas EL, Brynes AE, Hamilton G, et al. Effect of nutritional counseling on hepatic, muscle and adipose tissue fat content and distribution in non-alcoholic fatty liver disease. World J Gastroenterol. 2006;12(36):5813-5819.

48. Huang MA, Greenson JK, Chao C, et al. One-year intense nutritional counseling results in histological improvement in patients with non-alcoholic steatohepatitis: a pilot study. Am J Gastroenterol. 2005;100(5):1072-1081.

49. Haghighatdoost F, Salehi-Abargouei A, Surkan PJ, Azadbakht L. The effects of low carbohydrate diets on liver function tests in nonalcoholic fatty liver disease: a systematic review and meta-analysis of clinical trials. J Res Med Sci. 2016;21:53. doi: 10.4103/1735-1995.187269

50. Naude CE, Schoonees A, Senekal M, Young T, Garner P, Volmink J. Low carbohydrate versus isoenergetic balanced diets for reducing weight and cardiovascular risk: a systematic review and meta-analysis. PloS One. 2014;9:`e100652. doi: 10.1371/journal.pone.0100652

51. Nelson DL, Cox MM. Lipids. In: Nelson DL, Cox MM, editors. Lehninger Principles of Biochemistry. New York: W.H. Freeman and Company 6th edition. 2013;343-368.

52. Takeuchi H. Lipids. In: Tsuji H, Ebihara K, Watanabe H, Takeuchi H, editors. Introduction to food science (in Japanese). 3rd edition. Tokyo: Kodansha Ltd. 2016:60.

53. Ministry of Health, Labour and Welfare of Japan. Dietary Reference Intakes for Japanese, 2015 (in Japanese). Tokyo: Daiichi Syuppan Co. Ltd; 2014.

54. Lovejoy JC, Smith SR, Champagne CM, Most MM, Lefevre M, DeLany JP, et al. Effects of diets enriched in saturated (palmitic), monounsaturated (oleic), or trans (elaidic) fatty acids on insulin sensitivity and substrate oxidation in healthy adults. Diabetes Care. 2002;25(8):1283-1288.

55.Xiao C, Giacca A, Carpentier A, Lewis GF. Differential effects of monounsaturated, polyunsaturated and saturated fat ingestion on glucose-stimulated insulin secretion, sensitivity and clearance in overweight and obese, non-diabetic humans. Diabetologia. 2006;49(6):1371-1379. doi:10.1007/s00125-006-0211-x

56. Toshimitsu K, Matsuura B, Ohkubo I, Niiya T, Furukawa S, Hiasa Y, et 
al. Dietary habits and nutrient intake in non-alcoholic steatohepatitis. Nutrition. 2007;23(1):46-52. doi: 10.1016/j.nut.2006.09.004

57. Vilar L, Oliveira CP, Faintuch J, et al. High-fat diet: a trigger of nonalcoholic steatohepatitis? Preliminary findings in obese subjects. Nutrition. 2008;24(11-12):1097-102. doi: 10.1016/j.nut.2008.05.017

58. Westerbacka J, Lammi K, Hakkinen AM, Rissanen A, Salminen I, Aro A, et al. Dietary fat content modifies liver fat in overweight nondiabetic subjects. J Clin Endocrinol Metab. 2005;90(5):2804-2809. doi: 10.1210/jc.2004-1983

59. van Herpen NA, Schrauwen-Hinderling VB, Schaart G, Mensink RP, Schrauwen P. Three weeks on a high-fat diet increases intrahepatic lipid accumulation and decreases metabolic flexibility in healthy overweight men. J Clin Endocrinol Metab. 2011;96:E691-695. doi: $10.1210 / j \mathrm{jc} .2010-2243$

60. Takahashi M, Ikemoto S, Ezaki O. Effect of the fat/carbohydrate ratio in the diet on obesity and oral glucose tolerance in C57BL/6J mice. J Nutr Sci Vitaminol. 1999;45(5):583-593.

61. Ha SK, Chae C. Inducible nitric oxide distribution in the fatty liver of a mouse with high fat diet-induced obesity. Exp Anim. 2010;59(5):595604. doi: 10.1538/expanim.59.595

62. Longato L, Tong M, Wands JR, de la Monte SM. High fat diet induced hepatic steatosis and insulin resistance: role of dysregulated ceramide metabolism. Hepatol Res. 2012;42(4):412-427. doi: 10.1111/j.1872034X.2011.00934.X

63. Schattenberg JM, Galle PR. Animal models of non-alcoholic steatohepatitis: of mice and man. Dig Dis. 2010;28(1):247-254. doi: 10.1159/000282097

64. Capanni M, Calella F, Biagini MR, Genise S, Raimondi L, Bedogni G, et al. Prolonged n-3 polyunsaturated fatty acid supplementation ameliorates hepatic steatosis in patients with non-alcoholic fatty liver disease: a pilot study. Alim Pharmacol Ther. 2006;23(8):114311-51. doi: 10.1111/j.1365-2036.2006.02885.x

65. Boyraz M, Pirgon O, Dundar B, Cekmez F, Hatipoglu N. Long-Term Treatment with n-3 Polyunsaturated Fatty Acids as a Monotherapy in Children with Nonalcoholic Fatty Liver Disease. J Clin Res Pediatr Endocrinol. 2015;7(2):121-127. doi: 10.4274/jcrpe.1749

66. Li YH, Yang LH, Sha KH, Liu TG, Zhang LG, Liu XX. Efficacy of polyunsaturated fatty acid therapy on patients with nonalcoholic steatohepatitis. World J Gastroenterol. 2015;21(22):7008-7013. doi: 10.3748/wjg.v21.i22.7008

67. Dasarathy S, Dasarathy J, Khiyami A, Yerian L, Hawkins C, Sargent R, et al. Double-blind randomized placebo-controlled clinical trial of omega 3 fatty acids for the treatment of diabetic patients with nonalcoholic steatohepatitis. J Clin Gastroenterol. 2015;49(2):137-144. doi: 10.1097/MCG.0000000000000099

68. Petersen KF, Dufour S, Befroy D, Lehrke M, Hendler RE, Shulman GI. Reversal of nonalcoholic hepatic steatosis, hepatic insulin resistance, and hyperglycemia by moderate weight reduction in patients with type 2 diabetes. Diabetes. 2005;54(3):603-608. doi: 10.2337/ diabetes.54.3.603

69. Utzschneider KM, Bayer-Carter JL, Arbuckle MD, Tidwell JM, Richards TL, Craft S. Beneficial effect of a weight-stable, low-fat/low-saturated fat/low-glycaemic index diet to reduce liver fat in older subjects. $\mathrm{Br}$ J Nutr 2013;109(6):1096-1104. doi: 10.1017/S0007114512002966

70. Donnelly KL, Smith CI, Schwarzenberg SJ, Jessurun J, Boldt MD, Parks EJ. Sources of fatty acids stored in liver and secreted via lipoproteins in patients with nonalcoholic fatty liver disease. J Clin Invest.
2005;115(5):1343-1351. doi: 10.1172/JCI23621

71. Razavi-Zade M, Telkabadi MH, Bahmani F, Salehi B, Farshbaf S, Asemi Z. The effects of DASH diet on weight loss and metabolic status in adults with non-alcoholic fatty liver disease: a randomized clinical trial. Liver Int. 2016;36(4):563-571. doi: 10.1111/liv.12990

72. Wycherley TP, Moran LJ, Clifton PM, Noakes M, Brinkworth GD. Effects of energy-restricted high-protein, low-fat compared with standardprotein, low-fat diets: a meta-analysis of randomized controlled trials. Am J Clin Nutr. 2012;96(6):1281-1298. doi: 10.3945/ajcn.112.044321

73. Sacks FM, Bray GA, Carey VJ, Smith SR, Ryan DH, Anton SD, et al. Comparison of weight-loss diets with different compositions of fat, protein, and carbohydrates. N Engl J Med. 2009;360(9):859-873. doi: 10.1056/NEJMoa0804748

74. Johnston BC, Kanters S, Bandayrel K, Wu P, Naji F, Siemieniuk RA, et al. Comparison of weight loss among named diet programs in overweight and obese adults: a meta-analysis. JAMA. 2014;312(9):923-933. doi: 10.1001/jama.2014.10397

75. Ajala 0, English P, Pinkney J. Systematic review and meta-analysis of different dietary approaches to the management of type 2 diabetes. Am J Clin Nutr. 2013;97(3):505-516. doi: 10.3945/ajcn.112.042457

76. Hu T, Mills KT, Yao L, Demanelis K, Eloustaz M, Yancy WS Jr, et al. Effects of low-carbohydrate diets versus low-fat diets on metabolic risk factors: a meta-analysis of randomized controlled clinical trials. Am J Epidemiol. 2012;176: S44-54. doi: 10.1093/aje/kws264

77. Bueno NB, de Melo IS, de Oliveira SL, da Rocha Ataide T. Very-lowcarbohydrate ketogenic diet v. low-fat diet for long-term weight loss: a meta-analysis of randomised controlled trials. Br J Nutr. 2013;110(7):1178-1187. doi: 10.1017/S0007114513000548

78. Pagoto SL, Appelhans BM. A call for an end to the diet debates. JAMA. 2013;310(7):687-688. doi: 10.1001/jama.2013.8601

79. Sasaki S, Katagiri A, Tsuji T, Shimoda T, Amano K. Self-reported rate of eating correlates with body mass index in 18-y-old Japanese women. Int J Obes Relat Metab Disord. 2003;27(11):1405-1410. doi: 10.1038/ sj.ijo.0802425

80. Otsuka R, Tamakoshi K, Yatsuya H, Murata C, Sekiya A, Wada K, et al. Eating fast leads to obesity: findings based on self-administered questionnaires among middle-aged Japanese men and women. J Epidemiol. 2006;16(3):117-124. doi: 10.2188/jea.16.117

81. Hamada Y, Kashima H, Hayashi N. The number of chews and meal duration affect diet-induced thermogenesis and splanchnic circulation. Obesity (Silver Spring). 2014;22(5):E62-69. doi: 10.1002/oby.20715

82. Hamada Y, Miyaji A, Hayashi N. Effect of postprandial gum chewing on diet-induced thermogenesis. Obesity (Silver Spring). 2016;24(4):878885. doi: 10.1002/oby. 21421

83. Imai S, Matsuda M, Hasegawa G, Fukui M, Obayashi H, Ozasa N, et al. A simple meal plan of 'eating vegetables before carbohydrate' was more effective for achieving glycemic control than an exchange-based meal plan in Japanese patients with type 2 diabetes. Asia Pac J Clin Nutr. 2011;20(2):161-168.

84. Kuwata H, Iwasaki M, Shimizu S, , Minami K, Maeda H, Seino S, et al. Meal sequence and glucose excursion, gastric emptying and incretin secretion in type 2 diabetes: a randomised, controlled crossover, exploratory trial. Diabetologia. 2016;59(3):453-461. doi: 10.1007/ s00125-015-3841-z

85. Evert AB, Boucher JL, Cypress M, Stephanie A, Marion J, Elizabeth J, et al. Nutrition therapy recommendations for the management of adults with diabetes. Diabetes Care. 2013;36(11):3821-3842. doi: 10.2337/ dc13-2042 